\title{
ANALYSIS OF PERFORMANCE OF A TWIN-SHAFT GAS TURBINE DURING HOT-END DAMAGE IN THE GAS GENERATOR TURBINE
}

\author{
Samuel Cruz-Manzo \\ University of Lincoln \\ Brayford Pool, Lincoln, LN6 7TS, UK \\ scruzmanzo@lincoln.ac.uk
}

\author{
Festus Agbonzikilo \\ Siemens Industrial Turbomachinery \\ P. O. Box 1, Lincoln, LN5 7FD, UK \\ festus.agbonzikilo@siemens.com
}

\author{
Sepehr Maleki \\ University of Lincoln \\ Brayford Pool, Lincoln, LN6 7TS, UK \\ smaleki@lincoln.ac.uk
}

\author{
Yu Zhang \\ University of Lincoln \\ Brayford Pool, Lincoln, LN6 7TS, UK \\ yzhang@lincoln.ac.uk
}

\author{
Vili Panov \\ Siemens Industrial Turbomachinery \\ P. O. Box 1, Lincoln, LN5 7FD, UK \\ vili.panov@siemens.com
}

\begin{abstract}
In this study, an analysis of the performance of a twin-shaft industrial gas turbine (IGT) during hot-end damage in the gas generator turbine (GGT) at high-power operation has been carried out using a validated Simulink IGT model. The Simulink model is based on fundamental thermodynamics and allows the implementation of correlation coefficients in the GGT module to predict the performance of the IGT system during a hot-end GGT damage incident. Measured field data from a twin-shaft IGT operated as a power generation unit denoting a reduction in performance due to hot-end GGT damage are considered for the analysis. Four hot-end GGT damage incidents across a range of measured field data have been identified and considered for the analysis. The results show that the Simulink model can predict the change of physical parameters (pressure, temperature) across the IGT system for each GGT damage incident. Hot-end damage increases the flow capacity and reduces the efficiency of the GGT. Future work will validate the dynamic change of flow capacity and efficiency during different GGT damage incidents.
\end{abstract}

\section{INTRODUCTION}

Industrial gas turbines (IGTs) generate electrical power or drive rotatory machinery in different industrial applications. The gas generator turbine (GGT), also known as the compressor-turbine, drives the compressor in a twin-shaft IGT arrangement. During high power engine operation, the GGT inlet temperature limits the power output of the gas turbine. Typically, cooling on the trailing edge of the turbine blades is usually difficult to achieve, therefore during high temperature operation structural damage in this section of the bade can arise. In addition, the fact that the trailing edge of the turbine blades are composed of little material, the high temperature of the fluid leaving the combustor deteriorates this section of the blade. If a hot-end damage condition is present in the turbine, the flow capacity increases, and the efficiency decreases. According to Razak [1] the change in engine performance during a hot-end damage incident is mainly attributed to a reduction in the turbine efficiency. Some studies have been focused on the evaluation of failure in gas turbine blades. Zhou et al. [2] proposed a physical-based damage evaluation model for high temperature blades of gas turbines. The model can predict the thermodynamic performance, mechanical stress, and creep damage of the blades in gas turbines. The results show that it is possible to evaluate the online life of a turbine blade during high temperature operation. The model could also be a valuable tool for the reliability of gas turbines. Carter [3] reported the common failures in gas turbines blades. The mechanisms that affect turbine blades such as mechanical damage through either creep or fatigue and high temperature corrosion are discussed. Mishra et al. [4] analysed the failure of an un-cooled turbine blade in an aero gas turbine engine. The results showed that thermal cracks due to surface oxidation were found to be the cause of the blade failure. In addition, malfunction of sensors in the engine control system during high temperature operation was found responsible for initiating the thermal cracks. Kolagar et al. [5] investigated a first stage turbine blade failure in a $6.5 \mathrm{MW}$ gas turbine. Several 
experimental methodologies were applied to identify potential failure reasons such as: visual examination, fractography and microstructural characterization used by optical and scanning electron microscopes (SEM) and energy dispersive X-ray (EDX). The authors concluded that overheating was the main reason of blade failure. The mechanisms attributed to high temperature and low temperature hot corrosion in gas turbine components are discussed by Eliaz et al. [6]. High temperature hot corrosion is attributed to the condensation of fused alkali metal salts on the surface of the component. Low temperature hot corrosion results from the formation of $\mathrm{Na}_{2} \mathrm{SO}_{4}$ and $\mathrm{CoSO}_{4}$ with low melting temperatures. The authors concluded that the ultimate failure of turbine blades can result from the combination of hot corrosion and another failure mechanism (e.g. fatigue). Overall, the studies reported in the literature argue that overheating and corrosion are mechanisms that lead to blade failure. In this study, the change in the physical parameters across a twin-shaft IGT during an internal object damage incident in the GGT is estimated though a validated IGT Simulink model. Therefore, to simulate the change in physical parameters across the IGT during a GGT damage incident, non-dimensional coefficients which change the flow capacity and efficiency in the GGT have been implemented in the Simulink modelling architecture.

\section{GAS TURBINE MEASUREMENTS}

Measured field data such as pressure, temperature and speed from a twin-shaft IGT (sub $15 \mathrm{MW}$ ) operated during high power operation are considered for the analysis. Under this operating condition the GGT inlet temperature limits the power output. Hot-end damage incidents are attributed to consumption of the turbine material during internal object damage (IOD) events. The evidence that the data correspond to a twin-shaft IGT within GGT damage was corroborated after inspection. Four sets of measured data have been considered from the total range of measured data as hot-end damage incidents were present in the selected range of data. An Incident from the measured data has been related to the reduction in engine performance from an initial steady-state condition to the steady-state condition resulting from a GGT hot-end damage condition. A GGT hot-end damage incident was selected from each set of measured data. Each GGT damage incident has been named as Incident 1, 2, 3, 4 where Incident 1 corresponds to the earliest GGT damage condition and Incident 4 is the latest GGT damage condition. The four incidents represent the same defect but at different damage conditions in which the turbine is degraded with time. An example of how a GGT damage incident (Incident 1) has been identified is shown in Figs. 1, 2, 3 . Figure 1 shows the reduction in generated power during a GGT hot-end damage incident. The measured data have been normalised with respect to the data at $\mathrm{t}=0$. The decrease in the measured power output as well as the estimated GGT inlet temperature allowed the identification of GGT hot-end damage incidents in the measured data. During a GGT optimal condition, the generated power output is directly proportional to the GGT inlet temperature.
An increase in fuel demand should compensate the loss in power output; however, under the high-power engine operation condition, the maximum GGT inlet temperature limits the fuel demand.

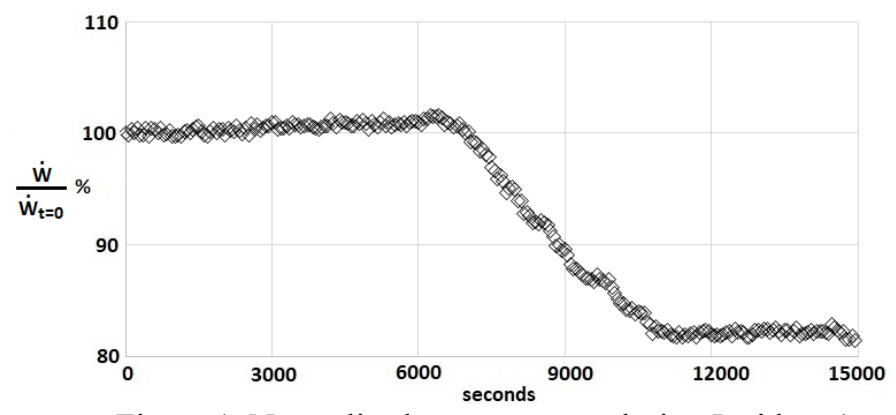

Figure 1. Normalised power output during Incident 1

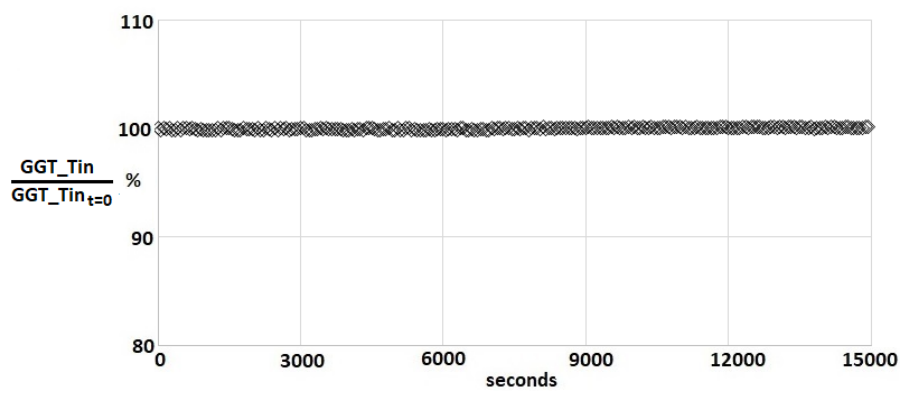

Figure 2. Normalised GGT inlet temperature during Incident 1

The GGT inlet temperature is an estimated parameter that considers measured temperatures across the compressor and interduct.

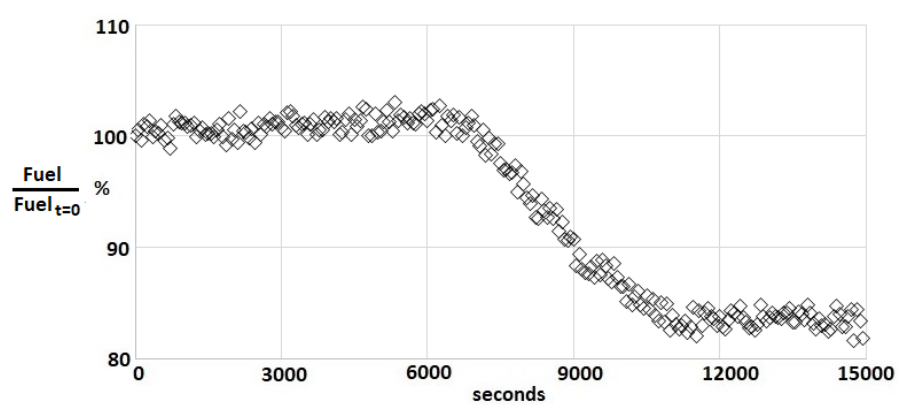

Figure 3 Normalised Fuel demand during Incident 1

The performance of the engine at high operating power is limited by the GGT maximum inlet temperature. This action is carried out by the controller in which the amount of fuel is regulated to not exceed the maximum GGT inlet temperature during engine operation. The GGT inlet temperature remains constant because it has the maximum value when the engine is operated at high power operating conditions. Figure 3 shows a decrease in fuel demand during the GGT damage-incident as the calculated temperature of the fluids entering the GGT as shown in Fig. 2 remains at the maximum value. The fuel demand shown in Fig. 3 is proportional to the power output shown in Fig. 1. 


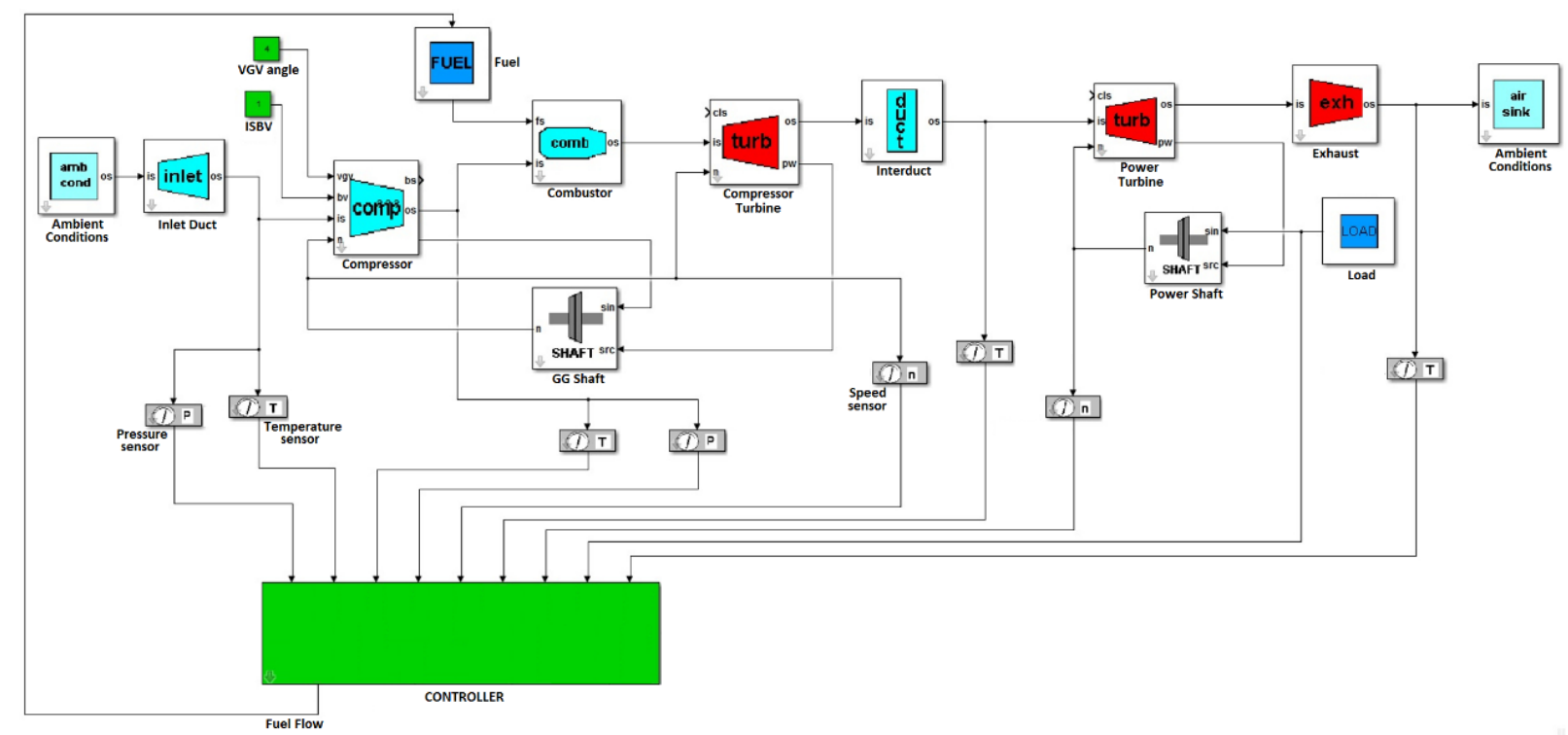

Figure 4. Simulink model architecture [7] for GGT hot-end damage

The non-dimensional flow capacity and efficiency of the GGT are not available in the measured field data. A validated IGT Simulink model will be used to predict the change in pressure and temperature across the IGT using the nondimensional coefficients that change the flow capacity and efficiency in the GGT during a hot-end damage incident.

\section{SIMULINK MODEL}

A Simulink model which can predict the performance of a twin-shaft IGT at different operating conditions is considered for the analysis, as shown in Fig. 4. A detailed description of the modelling architecture has been reported by Panov [7]. The Simulink model comprises thermodynamic equations based on energy conservation for thermodynamic systems [8]. Modelling assumptions have been considered to simplify the overall modelling architecture. conditions.

- The Simulink model considers only dry ambient

- No emissions such as oxides of nitrogen (NOx), carbon monoxide (CO) or unburned hydrocarbons (UHC) resulting from the fuel-air combustion are considered.

The Simulink model is comprised of two main groups of components representing industrial twin-shaft gas turbines, as shown in Fig. 5.

The Gas Generator group comprises the compressor, combustor, and GGT or compressor-turbine (CT). The Power Turbine group comprises the interduct between the GGT and power turbine, and the load. A mechanical shaft-bearing system connecting the compressor with GGT, and connecting the power turbine with driven load has been considered.

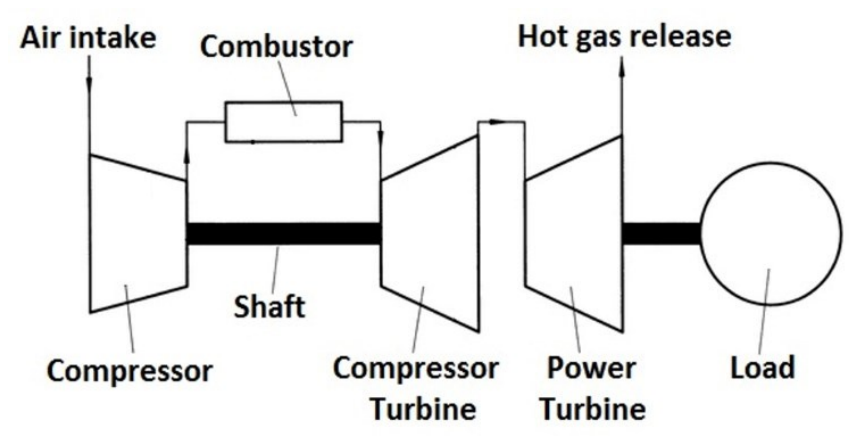

Figure 5. Twin Shaft IGT

The Simulink model requires as inputs the ambient conditions such as pressure and temperature, and demand load. A controller regulates the amount of fuel injected into the combustor based on the rotational speed and temperature and pressure across the different engine sections. During high power operation the GGT inlet temperature limits the power output. Performance component maps have been considered in the compressor, GGT, and power turbine components. The maps represent the performance of the overall multi-stage components with no failure conditions.

\section{Parameter Estimation for GGT Damage Analysis}

Performance maps representing no failure conditions in the components of the IGT have been implemented in the Simulink model. To estimate the performance of the twin-shaft IGT during GGT hot-end damage conditions, nondimensional coefficients have been implemented in the Simulink model to predict the change in flow capacity and efficiency in the GGT. 
It is possible to represent mathematical equations in the Simulink environment through defined blocks from the Simulink library. These blocks can represent mathematical operators and constants. The compressor module defined in the Simulink environment considers thermodynamic mathematical equations defined through blocks from the Simulink library [7]. The nondimensional coefficients were implemented in the Simulink environment using a constant block and a product block available in the Simulink library. A constant block together with a product block modify the value of the flow capacity and efficiency calculated by the equations defined in the compressor module. In addition, a toolbox available in the Simulink environment (Simulink Design Optimization) $[9,10]$ allowed the estimation of the nondimensional coefficients to predict the flow capacity and efficiency in the GGT and physical parameters across the different engine stations. Simulink Design Optimization toolbox from Simulink is a powerful computing resource which allows the optimization of physical system parameters to meet time-domain and frequency-domain requirements and increase a model accuracy [9]. The toolbox formulates parameter estimation as an optimization problem. The optimization-problem solution are the estimated parameter values. A sequence of steps is required during the optimization or estimation of the parameters. These steps consider data preparation, definition of parameters to estimate, optimisation algorithm, and the validation of the measured data with the simulated model response considering the estimated parameters. Different iterations for the parameter estimation are carried out until a minimum error between measured data and simulated data from the model is present. The optimisation of the nondimensional coefficients in the GGT using Simulink Design Optimization toolbox was carried out in two steps. First, the measured data at initial conditions and steady-state conditions were considered, thereafter the measured data attributed to GGT damage and final steady-state conditions were considered. These resulted in two different values of the nondimensional coefficients for initial and damage conditions respectively. An interpolation of the resulting values of the nondimensional parameters during the dynamic transition from GGT initial to GGT damage conditions was considered.

The nondimensional coefficients in the GGT should predict the change in pressure and temperature across the different modules of the twin-shaft IGT during a GGT damage incident. The flow and efficiency are not available in the measured data. The flow and efficiency predicted by the model were tuned or modified through the nondimensional coefficients such that the rest of the physical parameters such as pressure, temperature across the different sections of the IGT and calculated by the model predict the measured field data.

The compressor model assumes only standard variable guide vane (VGV) position. Therefore, depending on the actual VGV position it would be required to implement a parameter correction in the compressor module to account for VGV offset from nominal schedule. Actual VGV position depends on gas generator speed (GGS) and can differ for raising and falling speed. The estimation of the nondimensional coefficient in the compressor module to account for VGV offset is carried out in the same way as the estimation of the nondimensional coefficients for the GGT using the Simulink Design Optimization toolbox from Simulink.

\section{VALIDATION}

A comparison between measured and simulated physical parameters across the different modules of the twin-shaft IGT during a GGT hot-end damage incident has been carried out. The four measured GGT damage incidents previously mentioned in the gas turbine measurements section have been considered to validate the Simulink model. Figs. 6, 8, 9, 10, 11 and 12 show the comparison between measured and simulated data for the GGS, compressor discharge temperature and pressure, interduct pressure, interduct temperature, and exhaust temperature during the GGT Incident 1. The measured and simulated data have been normalised considering the measured data at $t=0$.

The physical parameters shown in Figs. 6, 7, 8, 9, 10, 11 and 12 correspond to the measured data for Incident 1 previously described in the gas turbine measurements section. Figs. 6, 8, 9, 10 and 12 demonstrate that the engine was operated at high operating power at steady state conditions (first 7000 seconds), thereafter a GGT damage condition was present (after 7000 seconds). The GGT damage condition is manifested in a transitory manner up to steady-state conditions. The results show that the model can predict the physical parameters across the IGT during steady-state conditions.

It is expected that a reduction in efficiency in the GGT yields a reduction in the GG speed, as shown in Fig. 6. This reduction of GG speed is followed with $\mathrm{VGV}$ position that corresponds to the falling VGV schedule.

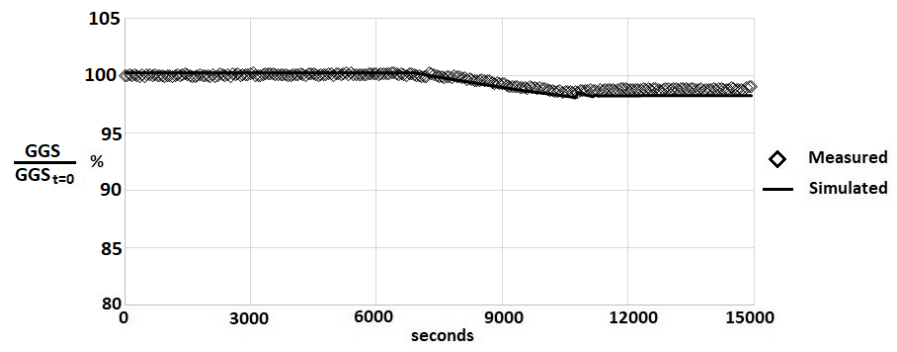

Figure 6. Comparison between measured and simulated gas generator speed for Incident 1

As previously mentioned, during a GGT damage incident, VGV position could differ from nominal schedule, as shown in Fig. 7. This VGV offset effect can also yield a reduction in compressor efficiency and increase in compressor exit temperature as shown in Fig. 8. 


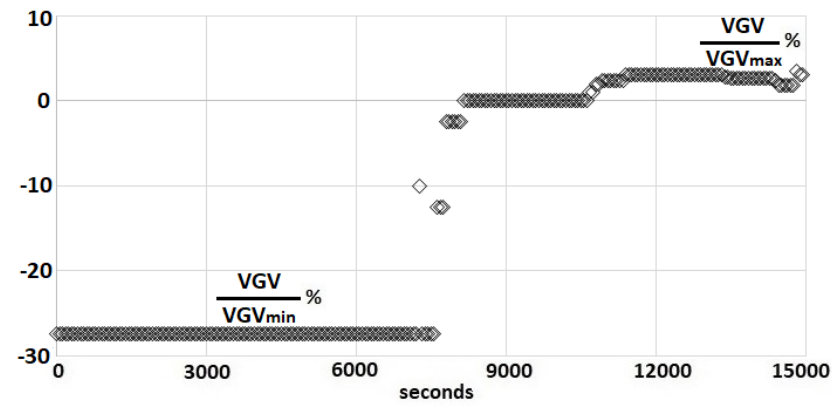

Figure 7. VGV position during Incident 1.

As a result of the VGV hysteresis effect, the compressor efficiency reduces, leading to a rise in the specific power of the compressor (increased compressor exit temperature). The reduced GG speed in Fig. 6 causes the compressor discharge pressure to drop correspondingly, as correctly depicted in Fig. 9. However, the reduction in compressor efficiency, owing to the VGV hysteresis effect, has much more overriding effect on the compressor exit temperature than the temperature drop that should expectedly accompany the reduced GG speed and compressor discharge pressure

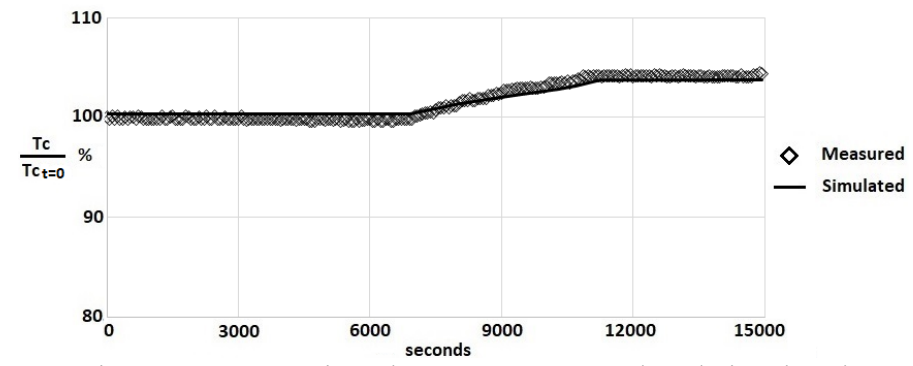

Figure 8. Comparison between measured and simulated compressor discharge temperature for Incident 1

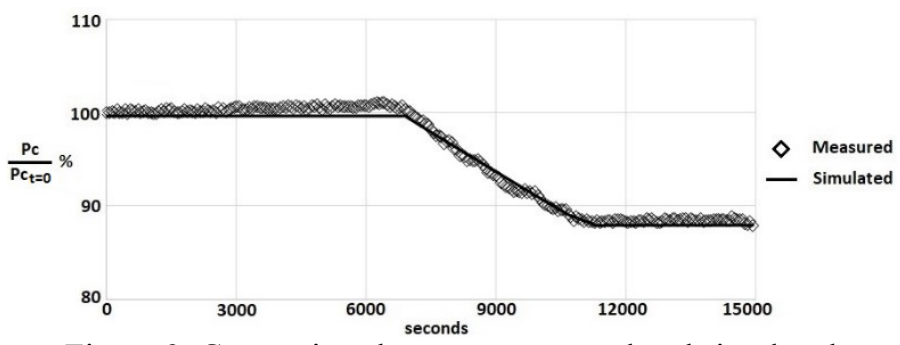

Figure 9. Comparison between measured and simulated compressor discharge pressure for Incident 1

The pressure across the IGT is reduced during a GGT damage incident. Fig. 9 shows a decrease in compressor discharge pressure during a hot-end damage incident. Fig. 10 shows a decrease in interduct pressure during Incident 1. During a GGT damage incident, there is an increase in flow capacity. The increase in GGT flow capacity leads to a variation of compressor pressure ratio with compressor rotational speed. Therefore, a reduction in compressor discharge pressure during a GGT damage incident is expected, as shown in Fig. 9.

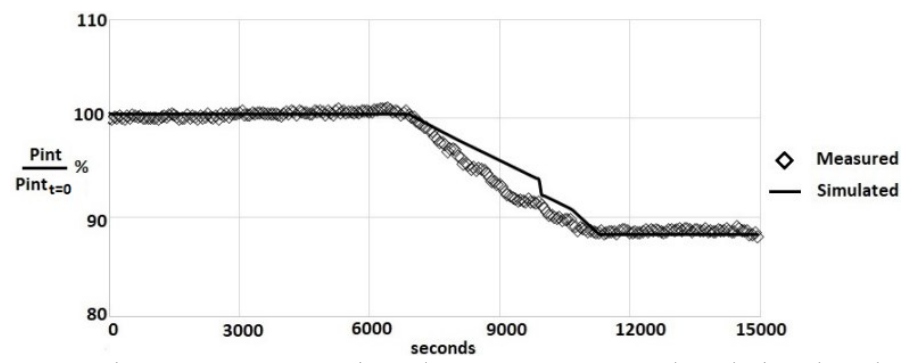

Figure 10. Comparison between measured and simulated interduct pressure for Incident 1.

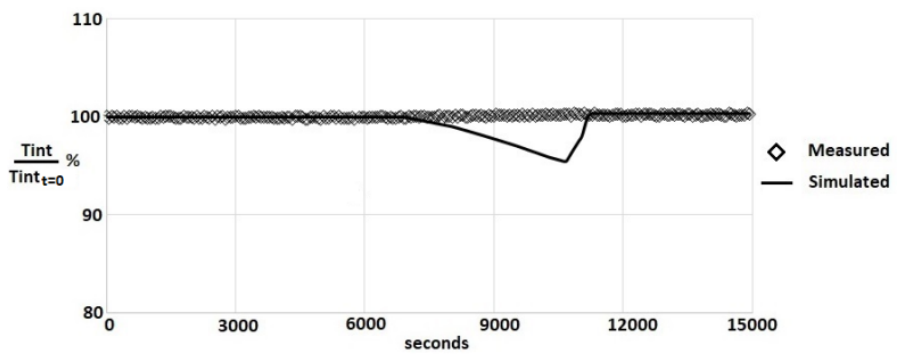

Figure 11. Comparison between measured and simulated interduct temperature for Incident 1

As previously mentioned, during a hot-end damage incident when the engine is operated at high power, the GGT maximum inlet temperature limits the performance of the engine. This action is carried out by the controller in which it reduces the amount of fuel demanded in order to maintain the GGT inlet temperature up to its maximum allowed value. The measured interduct temperature increases during the hot-end damage incident as well but the reduction in fuel from the controller maintains modest increase of interduct temperature during high engine power operation, as shown in Fig. 11. A discrepancy between measured and simulated interduct temperature and pressure during transient conditions is shown in Figs. 10 and 11. This discrepancy can be related to the fact that the dynamic variation of the nondimensional coefficients that change the flow and efficiency in the GGT during a GGT damage incident is not properly modelled. This will be address in the future by considering a physics base model for GGT damage. Nevertheless, it is possible to predict the steady-state variation of the physical parameters across the IGT during a hot-end damage incident in the GGT.

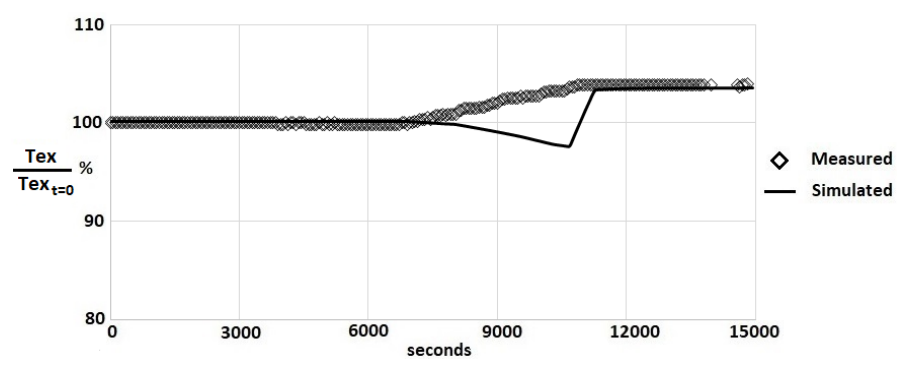

Figure 12. Comparison between measured and simulated exhaust temperature for Incident 1. 
In addition, the model could not properly capture the dynamic transition for the exhaust temperature of the hot fluids leaving the power turbine during the GGT hot-end damage incident, as shown in Fig. 12. This dynamic transition will be captured in future work as well which can assist in improving the control strategy during a GGT hot-end damage incident.

The error between measured data and simulated data at steady-state has been calculated for the four GGT hot-end damage incidents. The maximum error between measured field data and simulated data is $1.4 \%$, as shown in Table I. The error is calculated considering only steady-state conditions. The error for the comparison between measured and simulated data shown in Figs. 8, 9, 10, and 12 corresponds to Incident 1 shown in Table I.

\begin{tabular}{|c|c|c|c|c|c|}
\hline \multirow{2}{*}{ Incident } & & \multicolumn{4}{c|}{ \% Steady-state error } \\
\hline \multirow{2}{*}{1} & Initial condition & Comp_Temp & Comp_Pres & Interduct_Pres & Exhaust_Temp \\
\cline { 2 - 6 } & GGT Damaged & 0.74 & 0.31 & 0.522 & 0.36 \\
\hline \multirow{2}{*}{2} & Initial condition & 0.147 & 0.34 & 1.11 & 0.18 \\
\cline { 2 - 6 } & GGT Damaged & 0.2 & 0.1 & 0.57 & 0.128 \\
\hline \multirow{2}{*}{3} & Initial condition & 0.267 & 0.054 & 1.4 & 0.018 \\
\cline { 2 - 7 } & GGT Damaged & 0.282 & 0.048 & 0.205 & 0.092 \\
\hline \multirow{2}{*}{4} & Initial condition & 0.31 & 0.01 & 0.49 & 0.722 \\
\hline & GGT Damaged & 0.959 & 0.71 & 0.26 & 0.16 \\
& & & & 0.43 \\
\hline
\end{tabular}

Table I. Error between measured and simulated data for compressor discharge temperature, compressor discharge pressure, interduct pressure and exhaust temperature for the four GGT damage incidents.

\section{ANALYSIS OF RESULTS}

The change in flow capacity and efficiency in the GGT attributed to a hot-end damage incident is calculated using the Simulink model. The flow capacity is calculated as follows:

$Q=\frac{\dot{m} \sqrt{T}}{p}$

where $\dot{m}$ is the mass flow rate discharged by the GGT $(\mathrm{kg} / \mathrm{s})$, $T$ is the temperature entering the GGT $(\mathrm{K})$, and $p$ is the pressure entering the GGT (Pascal). During a GGT damage incident, there is a decrease in power output and a decrease in the fuel supplied to the combustor, as shown in Figs. 1 and 3. The decrease in fuel is related to an increase in GGT inlet temperature during a GGT damage incident. The GGT inlet temperature limits the power output. There is an increase in the flow capacity during a GGT damage incident. The reduction in the turbine efficiency has a negative impact on the IGT performance. The calculated delta increase of flow capacity and delta reduction of efficiency for the four GGT damage incidents are shown in Figs. 13, 14, 15, and 16. The \% variation (Delta) of the parameters for each incident is calculated considering initial and post damage conditions at steady-state. Incident 1 , as shown in Fig. 13 presents a higher absolute value for \% Delta power output than the other three GGT Damage incidents, shown in Figs. 14, 15, and 16. The absolute value for $\%$ Delta Capacity and \% Delta Efficiency is proportional to the absolute value for $\%$ Delta power output.
The power output at steady-state conditions just before Incident 3 decreased by $2.84 \%$ with respect to the power output at conditions just before Incident 1 . The power output at conditions before Incident 4 decreased by $3.06 \%$ with respect to the power output at conditions before Incident 1 . This reduction in power output at different GGT conditions as the engine continues operating after each GGT damage incident can be related to irreversible degradation mechanisms.

Incident 4 shown in Fig. 16 presents the minimum absolute value for Delta power output.

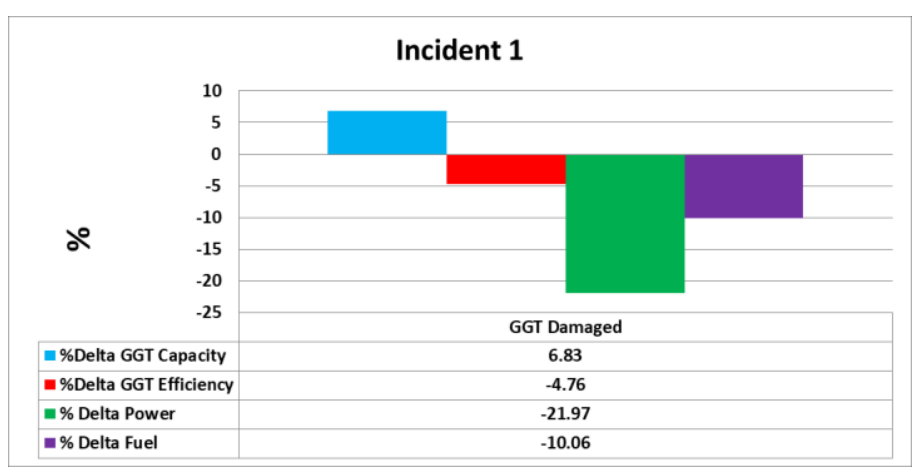

Figure 13. \% Delta for capacity, efficiency, power output, and Fuel demand for Incident 1.

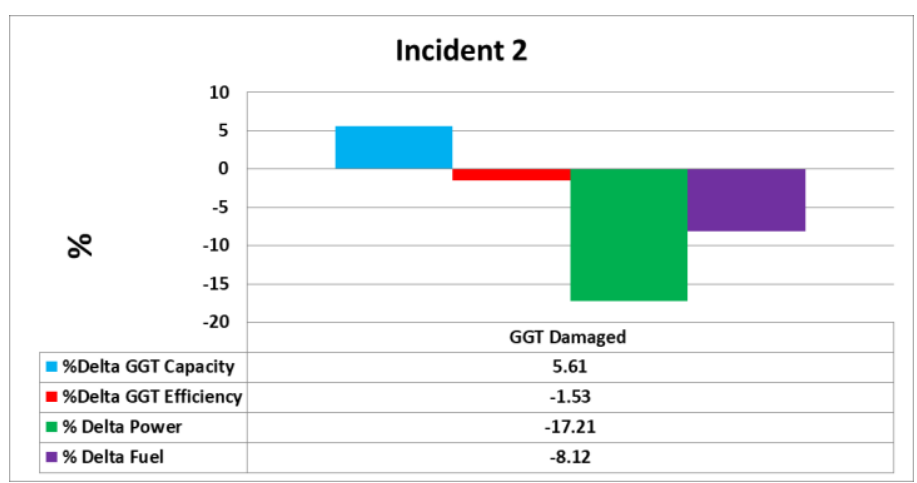

Figure 14. \% Delta for capacity, efficiency, power output, and Fuel demand for Incident 2.

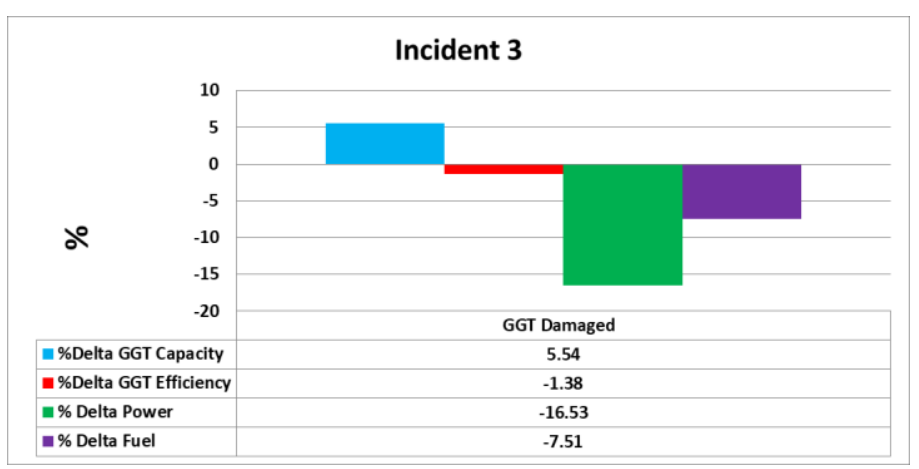

Figure 15. \% Delta for capacity, efficiency, power output, and Fuel demand for Incident 3. 


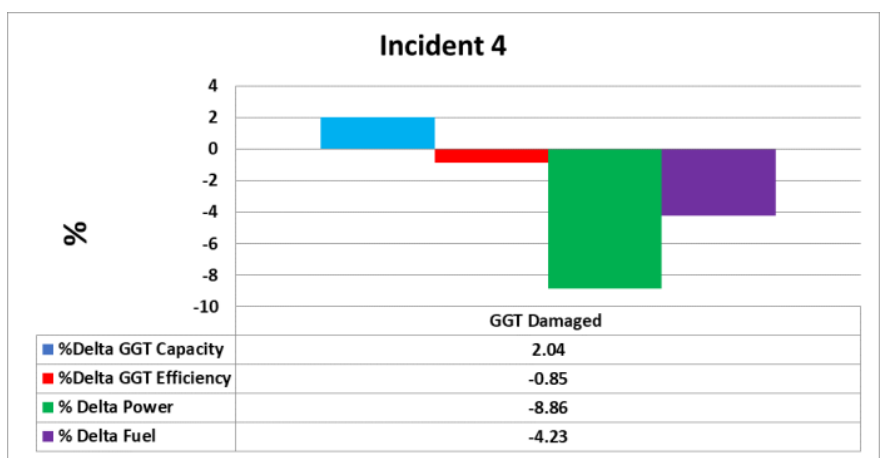

Figure 16. \% Delta for capacity, efficiency, power output, and Fuel demand for Incident 4.

The reason that case 4 presents a minimum \% Delta power with respect to the other cases is attributed to the reduction in power output after each incident. The reduction in power output can be related to degradation in the GGT material. The absolute value of \% Delta fuel demand during the GGT hot-end damage condition reduced from Incident 1 to Incident 4 as shown in Figs. 13, 14, 15, and 16. This effect can also be related to degradation or consumption of the turbine material during internal object damage (IOD) events. Irreversible degradation mechanisms in the GGT will be studied in future work.

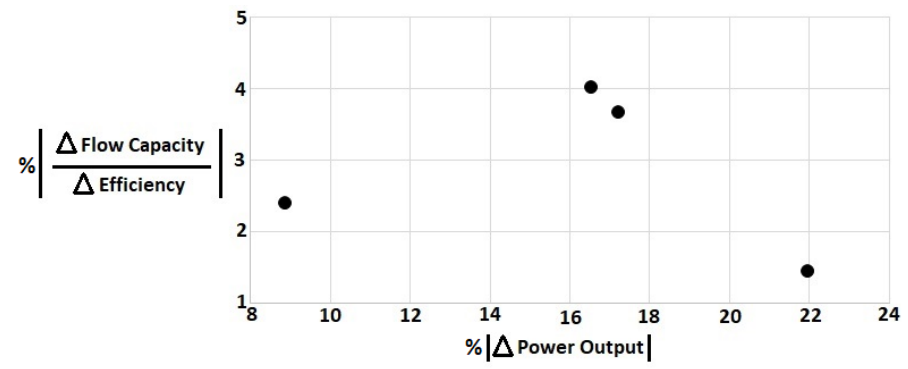

Figure 17. \% Absolute value of ratio Delta Capacity/Delta Efficiency with respect to \% absolute value of Delta Power output

The absolute value for the ratio \%Delta_Capacity/\%Delta_Efficiency is plotted against the absolute value of \% Delta power output, as shown in Fig. 17. It can be noticed that the $\%$ absolute value of the ratio between Delta capacity and Delta efficiency is low for two conditions. The first condition reflects the earliest GGT damage condition and the Delta parameters shown in Fig. 13. It expresses a high absolute \% Delta power output (21.97) between the power output at optimal conditions and GGT damage conditions. In this condition a higher reduction in efficiency and a higher increase in flow capacity were present with respect to the other cases. The second case reflects the latest GGT damage condition and the Delta parameters shown in Fig. 16. The figure reflects a minimum absolute \% Delta power output (8.86) between the power output before GGT damage conditions and after GGT damage conditions. Under this condition the power is reduced due to degradation mechanisms or consumption of the GGT material. It also demonstrates a lower reduction in efficiency and a lower increase in flow capacity with respect to the other cases. The relation \%Delta Capacity/\%Delta Efficiency needs further analysis as it could assist in the development of prognostic algorithms to predict failures in gas turbines related to GGT material degradation.

\section{CONCLUSION}

In this study, the performance of a twin-shaft IGT during GGT hot-end damage incidents has been analysed through a Simulink Model. Four GGT hot-end damage incidents were identified and selected from the range of measured data. Measurements such as temperature, pressure, and speed across an IGT were considered to validate this study. An empirical analysis based on estimated coefficients in the GGT from the Simulink model allowed the prediction of the change in physical parameters of the IGT during a GGT hot-end damage incident. The results demonstrate that the decrease of power and performance in an IGT during a GGT hot-end damage incident is attributed mainly to a reduced GGT efficiency.

\section{NOMENCLATURE}

GGS gas generator speed

GGT gas generator turbine

IGT industrial gas turbine

IOD internal object damage

$\mathrm{VGV}$ variable guide vane

Q flow capacity

m mass flow rate $(\mathrm{kg} / \mathrm{sec})$

$\mathrm{p} \quad$ pressure (Pascal)

$\mathrm{T}$ temperature (Kelvin)

\section{ACKNOWLEDGMENTS}

This research was supported by Siemens Industrial Turbomachinery, Lincoln, U.K.

\section{REFERENCES}

[1] V A. Razak, "Industrial Gas Turbines Performance and Operability", Woodhead Publishing Limited, (2007).

[2] D. Zhou, M. Chen, H. Zhang, S. Weng, "A Damage Evaluation Model of Turbine Blade for Gas Turbine", ASME Turbo Expo 2016: Turbomachinery Technical Conference and Exposition, Seoul, South Korea, June 13-17, 2016.

[3] T. J. Carter, "Common failures in gas turbine blades", Engineering Failure Analysis 12 (2005) 237-247.

[4] R. K. Mishra, J. Thomas, K. Srinivasan, V. Nandi, and R. R. Bhatt, "Failure analysis of an un-cooled turbine blade in an aero gas turbine engine", Engineering Failure Analysis, J. Eng. Fail. Anal., 79, (2017), pp. 836-844.

[5] A. M. Kolagar, N. Tabrizi, M. Cheraghzadeh, and M. S. Shahriari, "Failure analysis of gas turbine first stage blade made of nickelbased superalloy", Cases Studies in Engineering Failure Analysis, 8, (2017), pp. 61-68. 
[6] N. Eliaz, G. Shemesh, R. M. Latanision, "Hot corrosion in gas turbine components", J. Eng. Fail. Anal., 9, (2000), pp. 31-43.

[7] V. Panov, "GasTurbolib-Simulink Library for Gas Turbine Engine Modelling”, Proceedings of ASME Turbo Expo 2009, GT2009, June 8-12, Orlando, Florida, USA.

[8] S. Cruz-Manzo, et al. "A thermodynamic transient model for performance analysis of a twin shaft industrial gas turbine", Proceedings of ASME Turbo Expo 2017, GT201764376, June 26-30, Charlotte, NC, USA.

[9] Simulink Design Optimization 2013a, The MathWorks, Inc., Natick, Massachusetts, United States.

[10] S. Cruz-Manzo, S. Maleki, Y. Zhang, and V. Panov, and A. Latimer "Performance analysis of a twin shaft Industrial Gas Turbine at fouling conditions", IEEE International Conference on Prognostics and Health Management (ICPHM), 19-21 June 2017, Dallas, Texas. 